\title{
AC 2012-3147: HYBRID DELIVERY OF ENGINEERING ECONOMY TO LARGE CLASSES
}

\section{Kellie Grasman, Missouri University of Science \& Technology}

Kellie Grasman serves as an instructor in engineering management and systems engineering at Missouri University of Science and Technology. She holds graduate degrees in engineering and business administration from the University of Michigan and began teaching in 2001 after spending several years in industry positions. She was named the 2011-12 Robert B. Koplar Professor of Engineering Management for her achievements in online learning. She serves as an eMentor for the University of Missouri System and earned a Faculty Achievement Award for teaching.

\section{Dr. Suzanna Long, Missouri University of Science \& Technology}

Suzanna Long is an Assistant Professor with the Department of Engineering Management and Systems Engineering at Missouri University of Science \& Technology (formerly University of Missouri, Rolla). She holds a Ph.D. and an M.S. in engineering management, B.S. in physics, and a B.A. in history from the University of Missouri, Rolla (UMR), and an M.A. in history from the University of Missouri, St. Louis. Her research interests include strategic management of sustainable supply chain partnerships, transportation-logistics, supply chain management, engineering education, and organizational analysis.

Sean Michael Schmidt, Missouri University of Science \& Technology 


\section{Hybrid Delivery of Engineering Economy to Large Classes}

Abstract: The current forces of increasing student enrollments, limited classroom space, and increased budget constraints have led many to rethink the way courses are delivered, especially those with significant enrollment each semester. Advances in technologies that may support learning provide opportunities to increase efficiency while maintaining quality. This paper presents a hybrid approach to delivering an undergraduate Engineering Economy course to students at the Missouri University of Science and Technology. The hybrid mode blends online and face-to-face delivery methods, and allows students to utilize resources and access learning support in a "buffet" manner. This hybrid design incorporates technology to enhance learning, while increasing the opportunity for face-to-face interaction for students who desire that approach. Pedagogical structure and specific technology solutions are presented. Student perception, student performance, and specific learning outcomes in the hybrid class are compared to those of traditional lecture delivery.

\section{Introduction}

In a "hybrid" course, a portion of the activities that would normally take place in the classroom is shifted to an online format. The result is reduced classroom time without reducing the content of the course. A variant of the hybrid classroom is the "buffet" model, as described by Carol Twigg of the National Center for Academic Transformation ${ }^{1}$. In this approach, students are allowed to choose their preferred approach to the course from a buffet of learning options.

Inspired by these two models, and motivated by increasing course enrollments and reduced classroom space, the main author (referred to as "Instructor") sought to redesign an undergraduate engineering economics course. Further, incorporation of technology in the delivery of the course was desired and supported through grants from the Missouri University of Science and Technology and the University of Missouri System.

In Spring 2011, the Instructor taught two pilot sections of the undergraduate engineering economics course on the Missouri University of Science and Technology campus using the hybrid/buffet delivery mode. Only two sections were offered on campus in the first semester, therefore all students taking the course participated in one of these two hybrid/buffet sections. The course was again taught by the Instructor in Fall 2011, and once more delivered in hybrid/buffet mode. Minimal modifications were made to the course from its first hybrid/buffet offering in Spring 2011 to the second semester offered in Fall 2011. Limited data was collected in the first pilot section, but additional student surveys were incorporated in the Fall 2011 semester. Results from a comparison between the two hybrid/buffet semesters and the traditional face-to-face lecture delivery mode in past semesters are presented.

Many research studies have attempted to quantify the effects of delivery mode on student learning outcomes. The U.S. Department of Education Meta-Analysis and Review of Online Learning Studies ${ }^{2}$ combines the results of over 50 such experiments. The meta-analysis study found that online students performed modestly better than those learning with traditional face-toface instruction. Yet, instruction combining online and face-to-face elements (hybrid instruction) yielded an advantage over purely online instruction. Studies show some evidence 
that giving learners an element of control over the online resources they use produces greater learning gains than instructor-directed environments. While generalized results, these findings encouraged the Instructor's hybrid/buffet approach to the course.

In order to offer students a buffet of learning resources, a variety of course components were utilized. The course components were categorized as:

1. Online Resources

a. Instructor-Created Modules, consisting of Introduction videos with learning objectives, Lessons in both PowerPoint ${ }^{\mathrm{TM}}$ and video form, and Example problem videos.

b. WileyPLUS $S^{3}$, the online learning environment associated with Principles of Engineering Economic Analysis $5 e$ by White, Case and Pratt ${ }^{4}$, consisting of a digital copy of the text as well as Reading and graded Practice problem assignments.

2. Classroom Activities

a. Lessons, consisting of PowerPoint ${ }^{\mathrm{TM}}$ presentations with live annotation

b. In-Class Problem Solving with polling, consisting of examples solved by students and/or the instructor with audience response

3. Support Resources

a. Problem Solving Help, consisting of tutoring by skilled undergraduate Learning Assistants in a computer lab setting

b. Live Chat, consisting of real time question and answer sessions facilitated through a chat tool

c. Discussion Board, consisting of a thread for each Practice problem

A detailed description of each component is described in the following section. In general, students were encouraged to utilize the resources that they found most useful to them as individual learners. Students could choose to participate in the Classroom Activities each class meeting. With this approach, they would be exposed to all fundamental course topics through Lessons and Problem Solving guided by the Instructor in the classroom. Alternately, students could choose to access the Online Resources to review Modules independently. Students were not forced to choose an all-classroom or all-online approach and were free to change their mode of participation throughout the semester.

Although some students chose to attend regularly in the classroom while others preferred to review course material online, all students were assessed in the same manner. Course grades were determined by performance on four in-class exams ( $80 \%$ of overall grade) and weekly Practice assignments completed in WileyPLUS (20\% of overall grade). In addition to the online and classroom resources, students were provided both face-to-face and electronic Support Resources. Those students with questions about specific problems or issues with general topics could receive individual assistance in Problem Solving Help sessions or ask questions via online chat or a discussion board. 


\section{Online Resources}

\section{Instructor-Created Modules}

The hybrid/buffet course offered extensive Online Resources that students could access at any time throughout the semester. Resources were delivered from either Blackboard ${ }^{\mathrm{TM}}$, the standard campus learning management system, or from WileyPLUS, the online learning environment associated with the text. The Instructor-Created Modules were delivered via the course Blackboard ${ }^{\mathrm{TM}}$ site, which linked to the WileyPLUS site. Though it would have been ideal to deliver all content in one unified system, current technology did not allow the systems to be combined or all content to be delivered in only one system. However, new partnerships between learning management system developers and publishers promise to allow integrated solutions in the near future.

As the new hybrid/buffet course was developed, all course content was divided into learning objectives. Actionable learning objectives were then grouped by topic into Modules, with each module covering approximately 8-10 learning objectives. For each Module, a comprehensive set of resources was developed to prepare students to perform the learning objectives. Students were generally responsible for one Module each week, and materials were presented in a standard Module format on Blackboard ${ }^{\mathrm{TM}}$.

Each Module within Blackboard ${ }^{\mathrm{TM}}$ contained the same common components: Introduction, Read About It, Lessons, Examples, and Practice. Each Read About It and Practice component contained a link to the WileyPLUS site, where those resources were housed. Those components will be discussed in the next section. However, Introduction, Lessons, and Examples will be explained here.

The Introduction component of each Module offered students a summary of all learning objectives and a short (3-5 minute) video of the instructor explaining the significance of the module topics and relating those topics to previous topics and/or engineering practice. Students were encouraged to refer to the learning objectives as they read through the text and as they prepared for assessments over the module.

The Lessons component of each Module contained brief video lectures for each significant topic. The videos were created by using Camtasia ${ }^{\circledR}$ to record a PowerPoint ${ }^{\mathrm{TM}}$ presentation delivered by the Instructor on a tablet PC. The Instructor's voice and pen annotations were captured together with the PowerPoint ${ }^{\mathrm{TM}}$ slides and processed into short video clips. The result was a short "lecture" that students could replay, rewind, fast forward, and pause as they viewed online. Most video Lessons followed a similar format, presenting equations and theory followed by an example solved using one of several methods.

While it is difficult to convey the nature of the video lessons in a written format, the image in Figure 1 may help to clarify. 


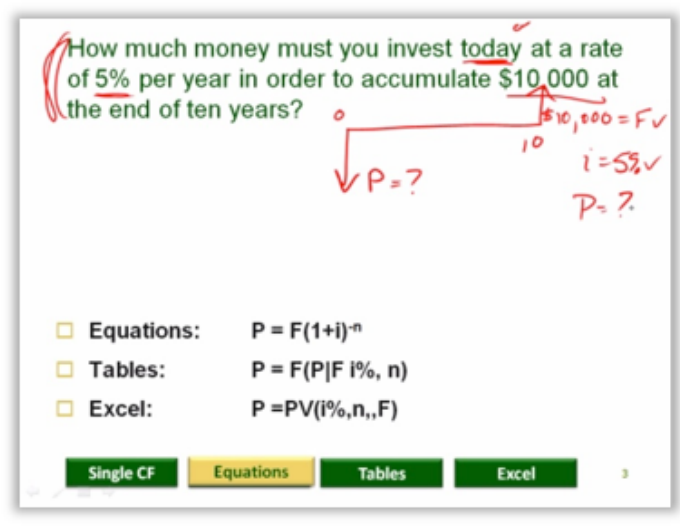

Figure 1 - Sample Lesson Slide

The underlying PowerPoint ${ }^{\mathrm{TM}}$ was carefully designed to allow the Instructor room to animate most slides, by writing on the computer screen, as the Lesson progressed. This mimicked the act of writing on the board in a traditional classroom and served to keep the student engaged and alert. Additionally, the slides were prepared with color-coded buttons on the bottom of the screen, offering a visual cue of what topic was being discussed at any given point in the video. This allowed students to replay a section or search for a specific topic or example within each video without the need to search randomly or replay entirely.

The Examples component of each Module presented solved example problems, many in video form. Some traditional pencil and paper problem solutions were prepared, scanned, and uploaded for student access. However, multiple video solutions were prepared for each Module as well. The video solutions were prepared by recording the computer screen of a tablet PC and voice narration using Camtasia ${ }^{\circledR}$ software. The video solutions often demonstrated multiple solution methods for each problem. For instance, a video may first display a "by hand" solution written on a virtual whiteboard. The same problem is also solved using factor tables, and the video displays the table on the screen while narration explains which column and row to use. Further, the video captures the keystrokes required to solve the same problem using Excel functions. Students are able to replay entire videos or sections of videos as needed.

\section{WileyPLUS}

The textbook used for the course, White, Case and Pratt's Principles of Engineering Economic Analysis $5 e^{4}$, offered significant digital resources through the corresponding WileyPLUS ${ }^{3}$ site. The detailed discussion of the general WileyPLUS product will be omitted here, as it may offer different resources for other textbooks. However, a summary of the resources used in this course will be presented. In general, the WileyPLUS site delivers a full digital version of the textbook as well as assessment tools. Students in the hybrid/buffet course were required to purchase access to the WileyPLUS site, and could do so in lieu of, or in conjunction with, purchasing a hardcover textbook.

The Read About It and Practice components mentioned above were located in WileyPLUS, and students were presented a link from Blackboard ${ }^{\mathrm{TM}}$ to the resources in WileyPLUS. The Read About It component was comprised of a specific reading assignment from the digital textbook. Each assignment linked students directly to the specific sections of a chapter that were relevant 
to the current Module. The Read About It assignments were not required but encouraged, and students could print sections of the digital textbook if they preferred to read on paper rather than a computer screen.

Practice assignments in WileyPLUS generally included 8-10 or more problems chosen from the end-of-chapter questions in the text or created by the Instructor. Most problems required students to analyze a situation, perform calculations, and report a numerical answer. All students were assigned the same problems, but many questions allowed for algorithmic generation of problem variables. Therefore, while all students were working with the same general problem statement and solution process, their numerical answers were unique. This feature allowed hundreds of students to complete the same assignment without the concern of students sharing answers with friends. The assessment functionality of WileyPLUS automatically checked the student's answer against the correct answer and offered immediate feedback, either correct or incorrect. Students were allowed three attempts to reach the correct answer, and were offered various forms of support with each problem.

Many assignable problems within the WileyPLUS system offered a "link to text" support, allowing students to click directly to the section of the digital textbook that discussed the material relevant to the specific problem. Further, some problems also offered "GO tutorials" which offered step-by-step guidance on the solution process for the problem. Students could practice solving the problem using the tutorial and then return to their original problem statement to apply the process. Additionally, some problems offered "video solutions" linked directly to the Practice problem. The solutions were similar in format to the Examples created by the Instructor, but provided within WileyPLUS.

\section{Classroom Activities}

As a compliment to the online resources provided through Blackboard ${ }^{\mathrm{TM}}$ and WileyPLUS, students could choose to attend live classroom sessions each week. In the classroom, Lessons were presented and In-Class Problem Solving was conducted with the support of live polling. The Lessons presented in the classroom were the same as the Lessons offered in video form on Blackboard $^{\mathrm{TM}}$. However, the Instructor delivered the Lessons live in the classroom and annotated the PowerPoint ${ }^{\mathrm{TM}}$ by writing on a tablet PC screen and projecting for student viewing. The classroom environment allowed students to ask questions during the Lesson, and students could choose to take notes on printable PowerPoint ${ }^{\mathrm{TM}}$ handouts or simply focus on the discussion. The Lessons were generally short, approximately 5-15 minutes in length, and introduced theory and equations as well as often a brief example.

In addition, students in the classroom participated in In-Class Problem Solving supported by a polling tool called Poll Everywhere ${ }^{5}$. Specifics about the features of this tool may be found at their website. While similar in practice to the use of "clickers" in the classroom, the students were able to respond to questions using mobile devices or laptops. For instance, students could text a response, tweet using Twitter or submit a response via any web browser. There was no cost to the students to respond to polls, other than any data fees associated with using their device. Students were not required to respond and responses were not graded, but many participated willingly and enjoyed the experience. The Instructor paid a nominal fee to 
accommodate a large number of respondents, but use of Poll Everywhere with small groups is free.

The Instructor would often insert several poll questions between Lessons. The Instructor could prepare a question in advance or create them in real time in the classroom. Both multiple choice and free response questions were created. Most questions presented an engineering economics problem requiring a numerical solution. Typically the question was projected for the class to view, and then students were asked to begin solving the problem independently or with a partner before the Instructor began discussing the solution. Additionally, students were often asked to respond to a question about their approach to a problem before solving. The anonymous poll responses were projected for the class to view. Occasionally students were also asked to respond to opinion questions, allowing the Instructor immediate perspective on topics such as students' perception of how clearly a topic was presented or the perceived difficulty of an assignment.

\section{Support Resources}

In an attempt to ensure all students had access to the resources they needed to succeed, additional Support Resources were provided throughout the semester. Problem Solving Help was offered approximately six hours per week in a computer lab setting. At least one knowledgeable Undergraduate Learning Assistant was available to answer student questions and/or assist with the solution of Practice problems. Students were also offered the opportunity to participate in Live Chat sessions with an Undergraduate Learning Assistant. Chat was conducted approximately six hours per week in the evenings, at a time when many students might be working on homework. Students could open a chat window on their computer and correspond by typing to get real time answers to questions. Further, a Discussion Board with individual threads for each Practice problem was available on Blackboard ${ }^{\mathrm{TM}}$. The Instructor often posted tips and hints for historically challenging problems, and students were encouraged to view these before beginning Practice assignments. Students were asked to post their questions to the Discussion Board, rather than emailing the Instructor directly. In that manner, either a fellow student could respond to the question or the Instructor would offer support and all students could benefit from the information.

\section{Student Feedback}

Though the initial pilot hybrid/buffet section was offered in Spring 2011, a detailed student survey was not administered until Fall 2011. In order to ensure anonymity, the survey was distributed online through Qualtrics ${ }^{\mathrm{TM}}$ and general demographic information was collected but not linked to individual students. Students were not required to participate in the survey. Out of 259 enrolled students, 71 (27\%) completed the survey.

The survey was divided into five general sections: Views \& Approach, Modules, WileyPLUS, Classroom, and Support. In addition, students were asked to provide some basic demographic data and self-report their anticipated letter grade for the course. Table 1 shows that the grade distribution of students who chose to participate in the survey is comparable to that of the actual assigned grade distribution for the course. And while the respondent pool may contain 
proportionately more A/B students than contained in the course as a whole, the survey results remain relevant and represent a reasonable distribution of the overall course.

Table 1 - Self-Reported Grades vs. Actual Class Grades

\begin{tabular}{|l|r|r|r|}
\hline & \multicolumn{1}{|c|}{ A/B } & \multicolumn{1}{c|}{ C } & \multicolumn{1}{c|}{ D/F } \\
\hline Actual Class Grades & $81.08 \%$ & $11.58 \%$ & $7.34 \%$ \\
\hline Reported Grades from Survey & $92.96 \%$ & $4.23 \%$ & $2.82 \%$ \\
\hline
\end{tabular}

A summary of select question responses is presented here. A thorough analysis of all survey questions may be presented in a different venue.

Table 2 indicates the reported distribution of attendance in the classroom relative to reported course letter grade.

Table 2 - Attendance Separated by Grade

\begin{tabular}{|l|c|c|c|c|}
\hline \multicolumn{5}{|c|}{$\begin{array}{c}\text { Please indicate which category most closely represents your in class } \\
\text { attendance in the lecture hall... }\end{array}$} \\
\hline & A/B & C & D/F & $\begin{array}{c}\text { Response } \\
\text { Total }\end{array}$ \\
\hline $\begin{array}{l}\text { Nearly every time the } \\
\text { class met }\end{array}$ & $30.00 \%$ & $33.33 \%$ & $0.00 \%$ & $29.69 \%$ \\
\hline $\begin{array}{l}60-80 \% \text { of class } \\
\text { meetings }\end{array}$ & $5.00 \%$ & $0.00 \%$ & $0.00 \%$ & $4.69 \%$ \\
\hline $\begin{array}{l}40-60 \% \text { of class } \\
\text { meetings }\end{array}$ & $6.67 \%$ & $33.33 \%$ & $0.00 \%$ & $7.81 \%$ \\
\hline $\begin{array}{l}20-40 \% \text { of class } \\
\text { meetings }\end{array}$ & $13.33 \%$ & $0.00 \%$ & $100.00 \%$ & $14.06 \%$ \\
\hline $\begin{array}{l}\text { Only as required the first } \\
\text { week of class }\end{array}$ & $45.00 \%$ & $33.33 \%$ & $0.00 \%$ & $43.75 \%$ \\
\hline Total & & & & $100 \%$ \\
\hline
\end{tabular}

It is clear that classroom attendance is not critical to success in the course, while those who are unsuccessful (D/F grades) may benefit from increased attendance. This topic may be explored in future work related to the course. 
Table 3 indicates the reported value to the students of each learning resource available in the hybrid/buffet course.

Table 3 - Value of Available Learning Resources

\begin{tabular}{|c|c|c|c|c|c|c|c|c|}
\hline \multirow[b]{2}{*}{ Learning Resource } & \multicolumn{5}{|c|}{$\begin{array}{l}\text { For each of the following that you used in this course, indicate its } \\
\text { value to you... }\end{array}$} & \multirow[b]{2}{*}{$\begin{array}{l}\mathrm{A} / \mathrm{B} \\
\text { Index }\end{array}$} & \multirow[b]{2}{*}{$\begin{array}{c}\mathrm{C} \\
\text { Index } \\
\end{array}$} & \multirow[b]{2}{*}{$\begin{array}{l}\mathrm{D} / \mathrm{F} \\
\text { Index }\end{array}$} \\
\hline & $\begin{array}{c}\text { Not at All } \\
\text { Valuable (- } \\
2)\end{array}$ & $\begin{array}{c}\text { Not } \\
\text { Valuable } \\
(-1) \\
\end{array}$ & $\begin{array}{c}\text { Neutral } \\
(0)\end{array}$ & $\begin{array}{c}\text { Valuable } \\
(1)\end{array}$ & $\begin{array}{c}\text { Very } \\
\text { Valuable } \\
(2) \\
\end{array}$ & & & \\
\hline Introduction & $1.67 \%$ & $1.67 \%$ & $33.33 \%$ & $48.33 \%$ & $15.00 \%$ & 0.65 & 2.00 & 1.00 \\
\hline Read About It & $9.09 \%$ & $7.27 \%$ & $40.00 \%$ & $38.18 \%$ & $5.45 \%$ & 0.22 & 0.67 & 0.00 \\
\hline Lessons & $0.00 \%$ & $0.00 \%$ & $12.31 \%$ & $46.15 \%$ & $41.54 \%$ & 1.30 & 1.67 & 0.50 \\
\hline Examples & $0.00 \%$ & $0.00 \%$ & $7.14 \%$ & $42.86 \%$ & $50.00 \%$ & 1.43 & 1.67 & 1.00 \\
\hline Practice & $1.45 \%$ & $0.00 \%$ & $7.25 \%$ & $42.03 \%$ & $49.28 \%$ & 1.41 & 1.33 & 0.50 \\
\hline $\begin{array}{l}\text { Instructor Office } \\
\text { Hours }\end{array}$ & $0.00 \%$ & $6.67 \%$ & $40.00 \%$ & $46.67 \%$ & $6.67 \%$ & 0.57 & 0.00 & N/A \\
\hline $\begin{array}{l}\text { Problem Solving } \\
\text { Sessions }\end{array}$ & $0.00 \%$ & $6.45 \%$ & $35.48 \%$ & $32.26 \%$ & $25.81 \%$ & 0.69 & 1.33 & 0.00 \\
\hline Discussion Board & $3.64 \%$ & $1.82 \%$ & $32.73 \%$ & $43.64 \%$ & $25.81 \%$ & 0.81 & 1.00 & 0.00 \\
\hline Online Chat Help & $0.00 \%$ & $23.81 \%$ & $38.10 \%$ & $28.57 \%$ & $9.52 \%$ & 0.32 & -0.50 & N/A \\
\hline $\begin{array}{l}\text { Friends or } \\
\text { Classmates }\end{array}$ & $0.00 \%$ & $12.77 \%$ & $27.66 \%$ & $38.30 \%$ & $21.28 \%$ & 0.76 & -0.33 & 0.50 \\
\hline Class in Lecture Hall & $4.08 \%$ & $4.08 \%$ & $32.65 \%$ & $40.82 \%$ & $18.37 \%$ & 0.68 & 0.33 & 0.50 \\
\hline
\end{tabular}

Each Index value was calculated by summing the product of the survey results and the percentage of respondents' answers to each question, indicating a general level of value for each resource categorized by letter grade. It is interesting to note that most students find the Lessons, Examples and Practice to be the most valuable resources in the course. Also, the students earning $\mathrm{D} / \mathrm{F}$ grades seem to find relatively little value in any of the many course resources.

\section{Measured Effectiveness}

Learning outcomes were assessed to determine the impact of the hybrid/buffet model on student learning. As the hybrid/buffet course was offered to all sections on campus in both Spring 2011 and Fall 2011, no control group was available to compare learning within a given semester. Therefore, baseline data from an offering of the course in the traditional format in Fall 2010 was compared to data collected from the two hybrid/buffet sections.

The assessment plan consisted of a comparison of student performance on eight exam questions covering select fundamental learning objectives of the course. The exam questions were presented to students in the final exam of all Fall 2010 sections delivered in a traditional manner. The same questions were then embedded in exams of the hybrid/buffet course in both Spring 2011 and Fall 2011. The Instructor was the same for all traditional and hybrid/buffet sections and all questions were delivered in the same pencil and paper format to all sections. The demographic differences in the student populations each semester are expected to be minimal due to the large number of students enrolled each semester (250-280 students per semester). Though no significant differences were anticipated, the average ACT score and high school core GPA were calculated for each semester and found to be comparable (see Table 4). 
Table 4 - Comparison of average ACT score and high school core GPA

\begin{tabular}{|l|l|l|l|}
\hline & Fall 2010 (traditional) & Spring 2011 (hybrid) & Fall 2011(hybrid) \\
\hline Average ACT Score & 26.8 & 27.1 & 26.7 \\
\hline $\begin{array}{l}\text { High School Core } \\
\text { GPA }\end{array}$ & 3.5 & 3.5 & 3.5 \\
\hline
\end{tabular}

Figure 2 summarizes student performance on the eight exam questions. The percentage of students who successfully demonstrated the learning objective (i.e. answered the exam question correctly) was calculated for students in the traditional course offered Fall 2010. Also, the percentage of students successful on each exam question was calculated for each hybrid semester and averaged. Figure 2 displays the difference in performance (hybrid minus traditional) for each learning objective.

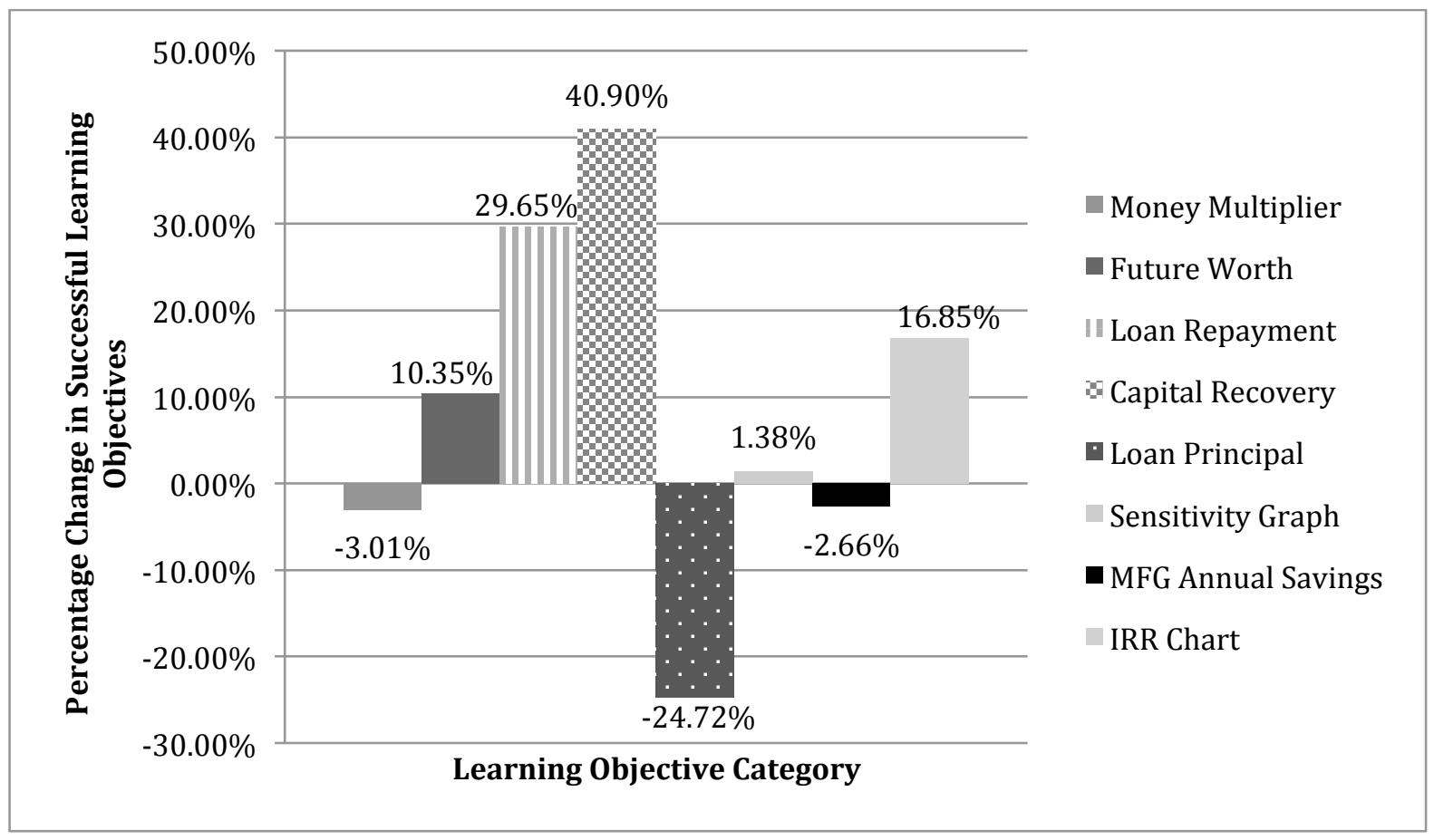

Figure 2 - Successful Learning Objective Difference (Hybrid - Traditional)

It may be noted that for most objectives, the students from hybrid sections appear to show a learning gain over students from the traditional sections. For learning objectives related to loan repayment and calculation of capital recovery cost, perceived gains of 30 to $40 \%$ are achieved. Other learning objectives show more modest gains, and two show small losses though it is uncertain if those small numbers represent true learning differences or merely normal variation. The one learning objective showing significant losses is that related to Loan Principal. This learning objective was measured by a question requiring students to calculate, without the use of a spreadsheet, the remaining principal on a loan immediately after making a specific payment. 
In the traditional sections, this calculation was demonstrated in the classroom on a chalkboard and students were required to repeat the calculation by hand on homework submitted on paper. However, in the hybrid sections, an increased emphasis was placed on spreadsheet solutions, especially for loan calculations. Further, students in hybrid sections completed their Practice problems on a computer with ready access to spreadsheet tools and were encouraged to use them. Therefore, it is logical to assume that hybrid students may have lost the ability to solve this problem using pencil and paper. However, an assessment of their ability to solve using a spreadsheet would likely yield comparable or improved performance relative to the traditional teaching approach.

In addition to comparing leaning outcomes, the distribution of final course letter grades was analyzed. Figure 3 compares the grade distributions for traditional and hybrid delivery methods. Grade distributions for traditional delivery methods were analyzed across five semesters (Fall 2008 through Fall 2010), while the grade distributions for the hybrid delivery were averaged over two semesters (Spring \& Fall 2011).

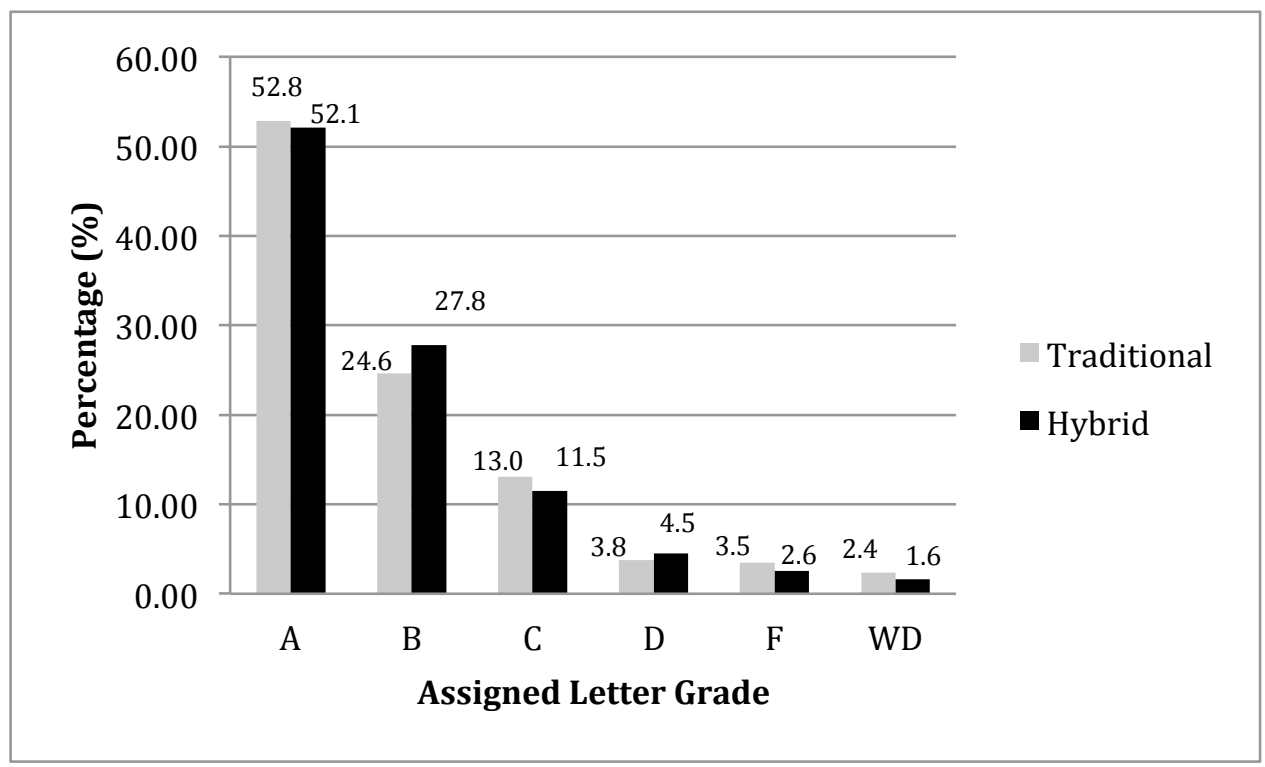

Figure 3 - Grade Distribution Comparison by Delivery Mode

It is important to note that the percentage of students who were unsuccessful in the course, those earning a letter grade of D or F or withdrawing before the semester finished, did not increase with the shift to hybrid delivery. The average percentage of unsuccessful students was $9.6 \%$ in traditional sections and $8.7 \%$ in hybrid sections. Therefore, though students in hybrid sections were not required to attend in the classroom their course performance did not suffer. 


\section{Conclusions and Future Work}

Overall, student response to the hybrid/buffet delivery mode has been positive. Students seem to enjoy the flexibility offered and value the accessibility and variety of learning resources.

Comments like the ones below were commonly found in end of semester evaluations of teaching for the course.

"The videos and examples are very helpful and supplement the in-class discussions very well. In addition, I really liked the text-messaging [polling] opportunities in class. It made it fun and engaging and helped keep me awake at 8AM in the morning. In addition, the questions really helped us check our understanding and get immediate feedback."

"[The instructor] really cares about whether or not the students understand the material. The problem solving sessions were very helpful, as were the online resources. It was nice to have all of the notes and the discussion board on Blackboard ${ }^{\mathrm{TM}}$. WileyPLUS was good too. It was a way to practice what we were learning and we could get an immediate response as to how we did."

While the majority of students are satisfied with the hybrid/buffet mode, some students do prefer a traditional approach. Even given the option to attend regularly in the classroom, some students would like attendance to be required instead of optional. However, offering choices rather than mandates is working for most.

For the Instructor, implementing the hybrid/buffet delivery mode involved significant challenges and investment of time. There was a steep learning curve involved in learning the technology tools required to execute the course. Further, development of course resources required many hours in advance of the first course offering. However, now that the online systems are organized it takes considerably less time to transition from one semester to the next.

In spite of the initial challenges, the Instructor now considers the hybrid/buffet an ideal delivery mode. Students who participated in the classroom were there by choice, and were generally willing and eager to learn and participate. Those who came to office hours generally had specific questions, and did not require the Instructor to re-teach material since it was available online. Most significantly, a shift was noted in student accountability and empowerment. Rather than viewing the course as something the Instructor must "teach" to them, many seemed to accepting individual responsibility for "learning" the course material. Offering choices to all students allowed individuals to decide how they learn best and created an environment of greater individual responsibility.

The subsequent impact on learning is demonstrated through improved performance on assessments of key learning objectives. Further, some students express the sentiment that they are really learning something they will remember and use again! This was reported by one student in end of semester evaluations of teaching for the course.

"I wish all my classes had all kinds of resources available like (course number). If anyone fails to get an A in this class, it is because they were lazy. Between class, Blackboard ${ }^{\mathrm{TM}}$, help 
sessions and WileyPLUS, I was really able to actually learn something, contrary to my other classes where I remember it for the semester and immediately forget it."

The Instructor is eager to continue to deliver this course in hybrid/buffet mode. However, since $60-70 \%$ of students chose to attend in the classroom only for assessments, the course may be offered for entirely online delivery to some students. The Instructor is experienced teaching small sections of the course in online mode, but the online assessments are cumbersome and time consuming to execute for large numbers of online students. Future work will involve creating an assessment strategy for online students that is manageable for the Instructor and preserves the academic integrity of the course.

While the rate of student success, as measured by the percentage of students obtaining a passing grade, is comparable to traditional delivery mode, the Instructor would like to improve this measure. Given the abundance of assessment data available in WileyPLUS and Blackboard ${ }^{\mathrm{TM}}$, it would be simple to implement an early warning system that could catch underperforming students early in the semester and encourage or mandate changes to help promote success.

As the course is refined over future semesters, detailed analysis of student surveys will be used to track changes is perception of the delivery mode, utilization of course tools, and the like. Further, performance and learning objective data over time will be analyzed for statistical significance. This work will inform modifications to enhance the course in future semesters. Modifications to the course will be monitored and impact on performance and perception will be quantified.

1. Twigg, C.A., "Improving Learning and Reducing Costs: Redesigning Large-Enrollment Courses", The Pew Learning and Technology Program, Troy, New York (1999). Available from Center for Academic Transformation, Rensselaer Polytechnic Institute http://www.center.rpi.edu.

2. U. S. Department of Education, Office of Planning, Evaluation, and Policy Development, Evaluation of Evidence-Based Practices in Online Learning: A Meta-Analysis and Review of Online Learning Studies, Washington, D.C., 2010.

3. WileyPLUS, http://wileyplus.com/. Last visited March 2012.

4. White, J.A., Case, K.E., and Pratt, D.B. (2009). Principles of Engineering Economic Analysis 5e. Wiley, New York, NY.

5. Poll Everywhere, http://polleverywhere.com/. Last visited March 2012. 